تأثير معدنية وجيوكيميائية صخور البلاسبي (الايوسين الأعلى المتوسط) في جبل عين الصفرة على مياه الينابيع

$$
\begin{aligned}
& \text { عبد الهادي يحيى الصائغ ليل حجي يوسف زنكنة } \\
& \text { قسم علوم الأرض المغ } \\
& \text { كلبة العلوم } \\
& \text { جامعة الموصل }
\end{aligned}
$$

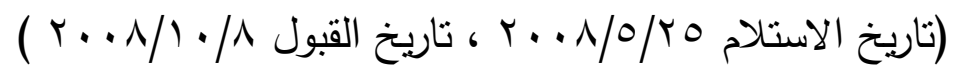

الملخص

إن صخور تكوين البلاسبي (M.Upper Eocene ) للجناح الثمالي الثرقي لطية عين الصفرة

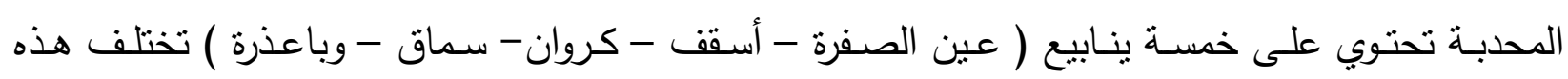
الصخور من حيث نسبة نواجد معدني الكالسايت والدولومايت و الحجم الحبيبي وكثافة الفواصل والثقوق و ولثئ تراكيز العناصر الكيميائية فيها.

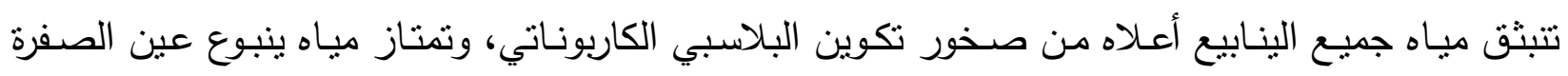

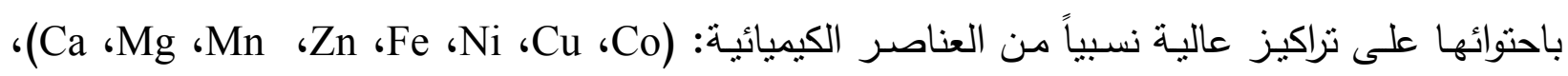

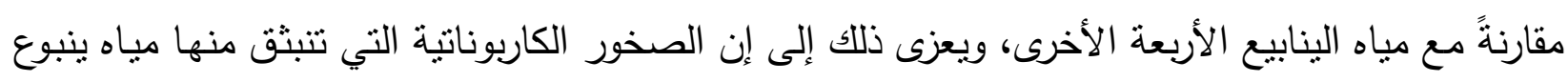

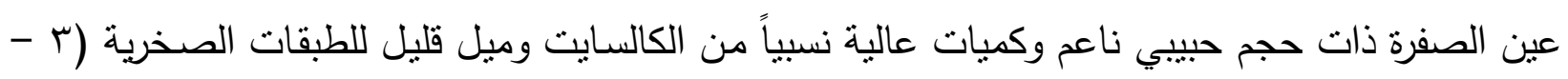

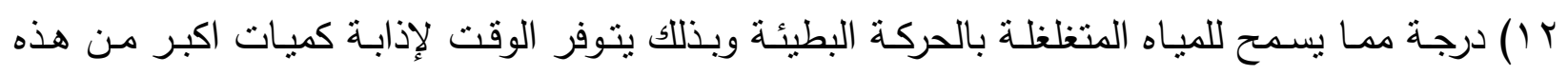

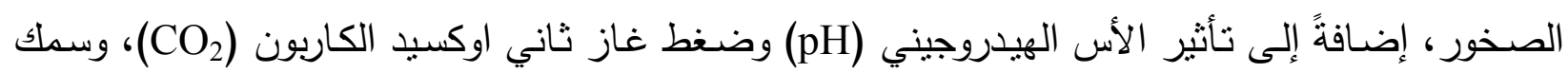

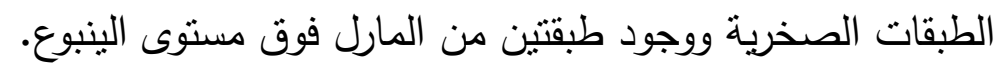




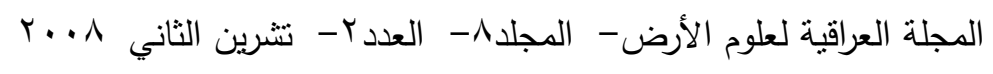

\title{
The Effect of the Mineralogy and Geochemistry of Pila Spi Rocks (M.U.Eocene) at Jabal Ain Al-Safra on the Spring Waters
}

\author{
Abdul Hadi Y. Al Sayegh Khalil H.Y. Zankana \\ Department of Geology \\ College of Science \\ Mosul University
}

\begin{abstract}
The major part of the exposed anticline of Jabal Ain Al - Safra consists of Pila Spi Formation (M.U.Eocene) and contains five water springs (Ain Al- Safra, Squf, karawan, Semmak Baadra).

The Pila Spi rocks consist of different proportions of calcite and dolomite at different areas, within the eastern limb of Jabal Ain Al- Safra anticline. Grain size, joints densities and fractures are also different.

The present study has concluded that Ain Al- Safra waters compared with other spring waters within the area have high concentration of the ions of $(\mathrm{Ca}, \mathrm{Mg}, \mathrm{Mn}, \mathrm{Fe}$, $\mathrm{Cu}, \mathrm{Co}$ ) especially manganese (Mn).this is possibly because the under ground waters before reaching Ain Al- Safra spring pass through relatively thick gently dipping rocks, rich in calcite and have fine grain size and also pass tow layers of marl interbedded with carbonate rocks.

These conditions plus the pressure of $\mathrm{CO}_{2}$ and the effect of the $(\mathrm{pH})$ value allow water to dissolve carbonate minerals and becomes relatively enriched in the above ions.

\section{المقدمة}

اكتسبت طية عين الصفرة (الجناح الثمالي الثرقي ) أهمية خاصة وذلك لوجود خمسة ينابيع فيها وهي: ( عين الصفرة، اسقف، كروان، سماق، باعذرة ) التي تتبثق مياهها من الصخور الكاربوناتية لتكوين

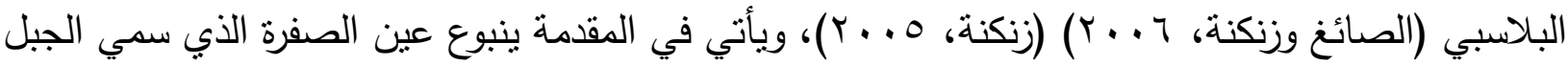

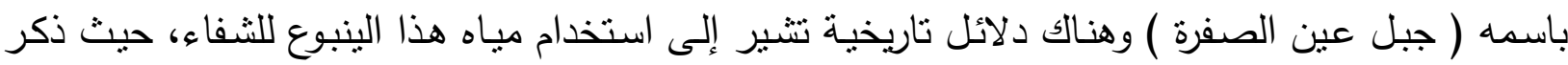

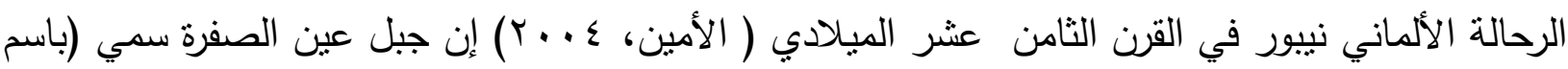

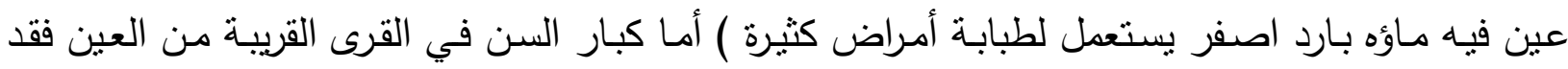

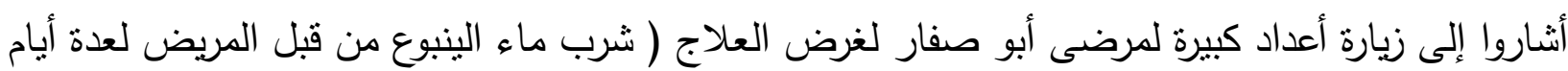

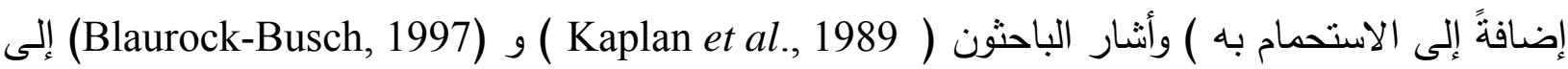
إن نقص عنصر المنغنيز (Mn) في جسم الإنسان يؤدي إلى الإصـابة بأمراض منها أبو صفار ( اليرقان )

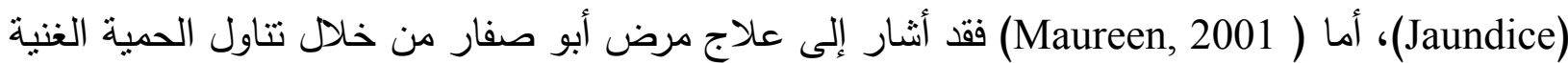
بعنصري الكالسيوم والمغنيسيوم التي نؤدي إلى بناء كريات الدم الحمراء التي فقدت بسبب المرض، وتؤدي
\end{abstract}




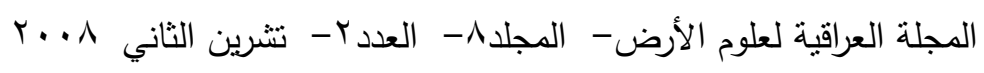

أيضاً إلى تخفيف التشنج لعضلات قناة الصفراء التي كانت تمنع إفراز المادة الصفراء خارج الجسم. لذا فأن شرب مـاء عين الصفرة الغني نسبياً بالعناصر الثناثنة أعلاه وبقية العناصر الكيميائية الأخرى سيؤدي إلى اكتساب المريض الثفاء، حيث إن هذه العناصر تعدل في مجاميع وبنسب مختلفة مـع بعضها البعض في

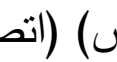
(الأيسان إز الفعالي.

د. فارس ذنون العباجي- كلية الصيدلة - جامعة الموصل، ؟ . . ؟). يهدف البحث الحالي إلى دراسة معدنية وتوزيع العناصر الرئيسة والأثرية في صخور تكوين البلاسبي وتأثنرها على مياه الينابيع في منطقة الدراسة.

\section{الموقع وجيولوجية المنطقة}

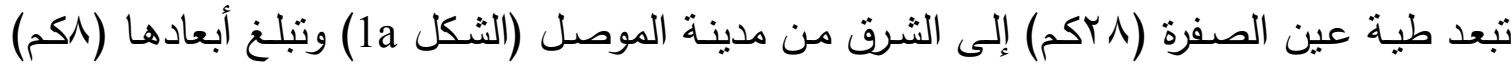

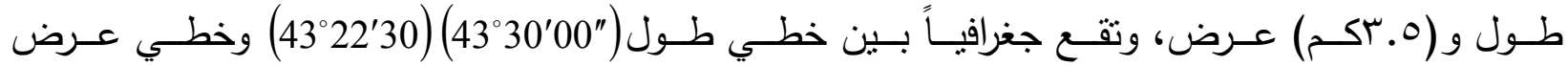

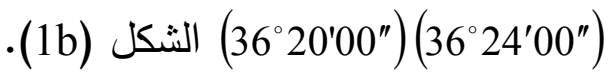
إن التكوينات الجيولوجية التي تظهر مكاشفها على سطح الأرض في منطقة الدراسـة موضحة في (الثكل r)، وتشكل تكوين البلاسبي (Pila Spi Fn.) هيكل طية عين الصفرة المحدبة، وهي عبارة عن صـور كاروبوناتيـة عديدة هي: صـخور دولوسـتون وصـخور جيريـة دولوماتيـة وصـخور دولوماتيـة جيريـة وفتانية، ويبلغ السمك الكلي للتكوين (100 (1) متراً، ويفصل هذه الطبقات بعضها عن بعض مستويات تطبق

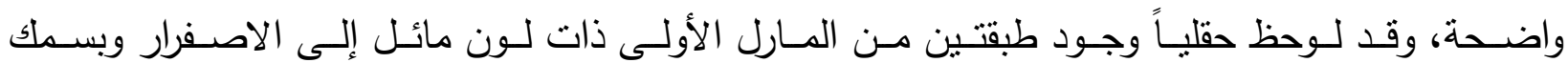
( • سم) سم، أما الثانية وهي الأحدث ذات لون اخضر وتقعان فوق مستوى الينبوع (زنكنة، ه . . ب)،ولم يلاحظ

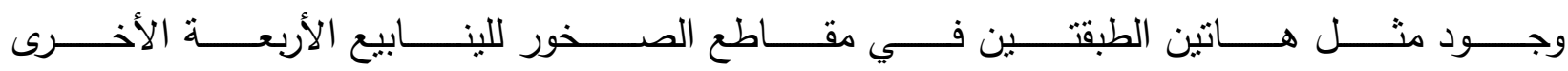
(الصائغ وزنكنة، 7 × . Y).أما من الناحية التركيبية فأن طية عين الصفرة تقع ضمن نطاق أقدام الجبال من الرصيف الغير المستقر للسطيح العربي ألنوبي (Buday and Jassim, 1987). إن زاويـة ميل طبقات

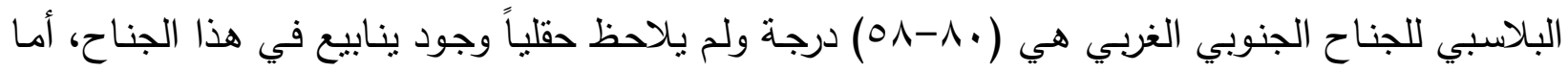
زاوية ميل طبقات البلاسبي للجناح الشمالي الثرقي ثتراوح بين (r إ- ؟؟) درجة وتتنشر الينابيع الخمسة في هذا الجناح: (عين الصفرة، أسقف، كروان، سماق، باعذرة ) ويرمز للينابيع بالرموز : (E,D,C,B,A) على التوالي كما في الثكل (1b). ومن الجدير بالذكر إن مياه هذه الينابيع تتأثر بشكل ملحوظ بكميات الأمطار في منطقة الدراسة حيث تزداد كمية المياه في حوض الينبوع في مواسم الأمطار وتتخفض في مواسم الجفاف ( زنكنة، 0. . . ب).

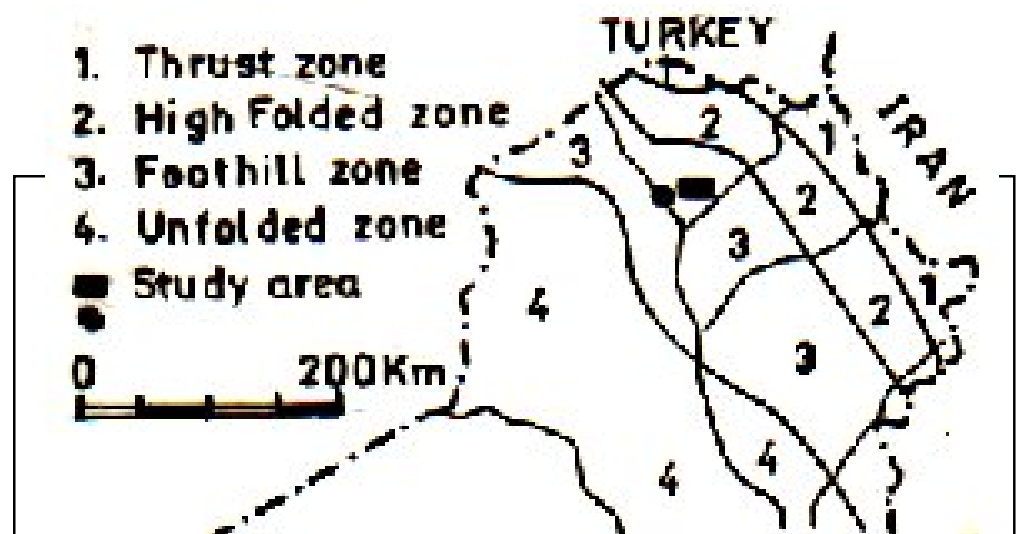




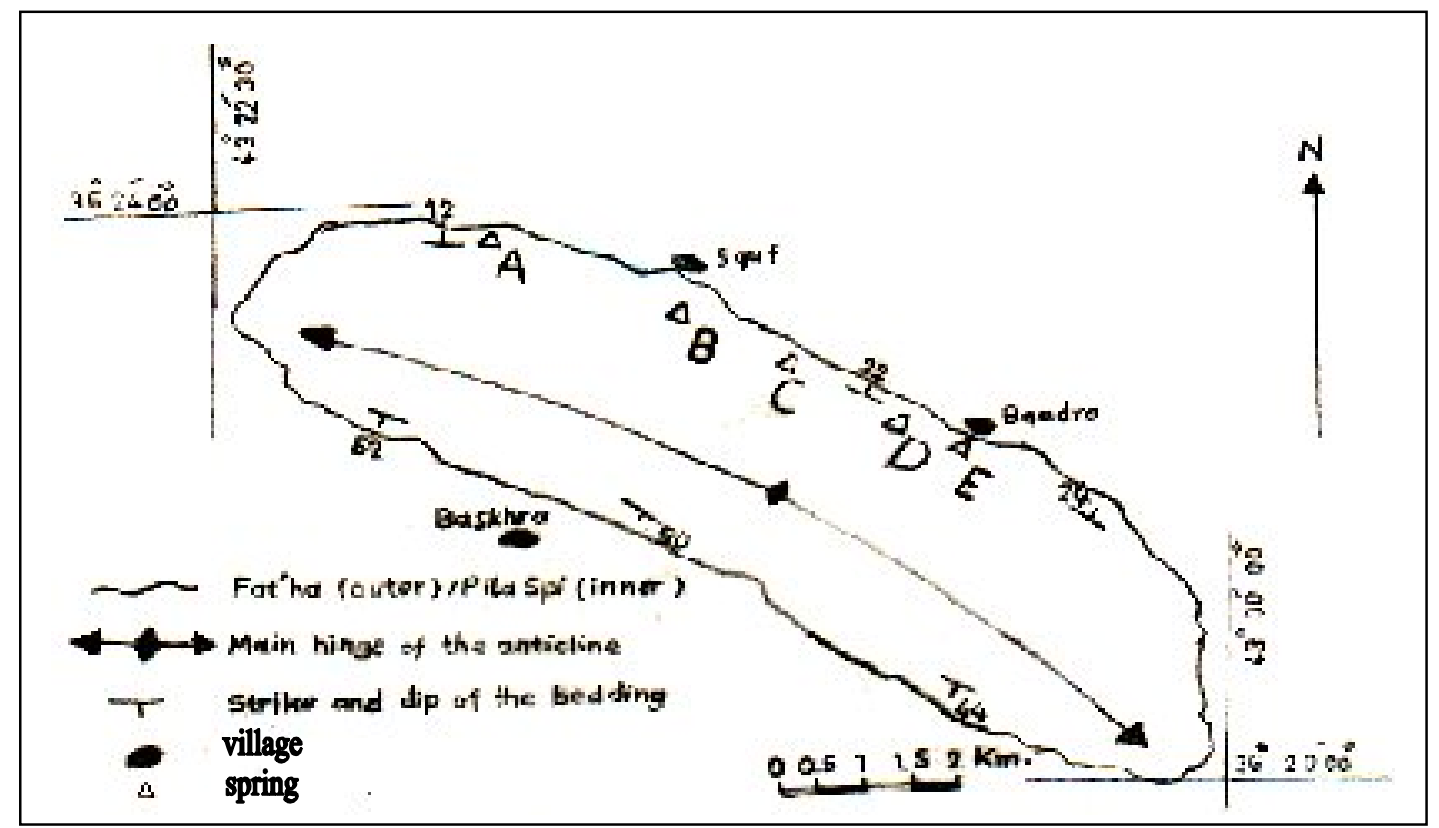

الشكل 1b: منطقة الدراسة،محور عن (Ibrahim and Omer, 1994).

\begin{tabular}{|c|c|c|c|c|}
\hline \multirow[b]{2}{*}{ 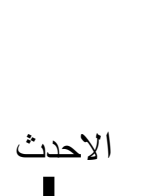 } & Formation & Age & Lithology & Thikness (m) \\
\hline & Muqdadia & $\begin{array}{l}\text { Lower } \\
\text { Pliocene }\end{array}$ & $\begin{array}{l}\text { Coarse- medium pebbly sandstone, } \\
\text { siltstone and compacted claystone. }\end{array}$ & 440 \\
\hline & Injana & $\begin{array}{l}\text { Upper } \\
\text { Miocene }\end{array}$ & $\begin{array}{l}\text { Fine medium well bedded sandstone, } \\
\text { siltstone and compacted claystone. }\end{array}$ & 235 \\
\hline & Fat'ha & $\begin{array}{l}\text { Middle } \\
\text { Miocene }\end{array}$ & $\begin{array}{l}\text { Massive and bedded gypsum, marly } \\
\text { limestone, marl and claystone. }\end{array}$ & $\begin{array}{l}121 \\
\text { Unconformity }\end{array}$ \\
\hline & Di1n Cni & Upper & Chalky, hard well bedded, thickly & 10 \\
\hline
\end{tabular}
دم

Barwari, 1983, Al- الثكل r: العمود الطباقي الصخري لمنطقة الدراسة محور عن

.(Omari and Sadek, 1973 


\section{طرق التحليل}

تم جمع وتحليل (آس) نموذجا صخريا قريبا من ينابيع الدراسة، وبشكل يتتاسب مع سمك الطبقات

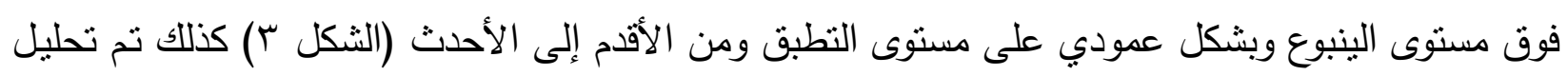

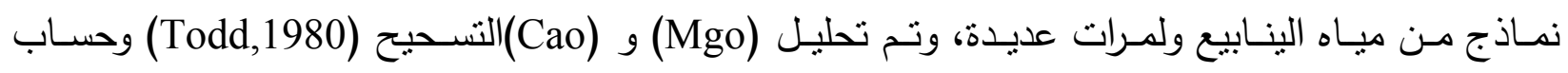
واعتماداً على جدول (Muller, 1956 ) $\mathrm{CaMg}\left(\mathrm{CO}_{3}\right)_{2} \%, \mathrm{MgCO}_{3} \%, \mathrm{CaCO}_{3} \%$,

M.W.CaMg $\left(\mathrm{CO}_{3}\right)_{2}$

Dolomite $\%=$ M.W. $\mathrm{Mg} \mathrm{CO}_{3}$

Calcite $\%=\mathrm{CaCO}_{3} \%+\mathrm{MgCO}_{3} \%$ - Dolomite $\%$ M.W.

وتم إيجاد تراكيز العناصر الأثرية في الصخور والمياه (Mn, Zn , Fe , Ni, Cu , Co ) باستخدام جهاز الامتصاص الذري - قسم علوم الأرض - جامعة الموصل وتم إيجاد تراكيز الكالسيوم والمغنيسيوم في

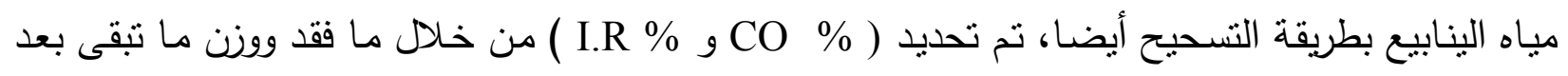

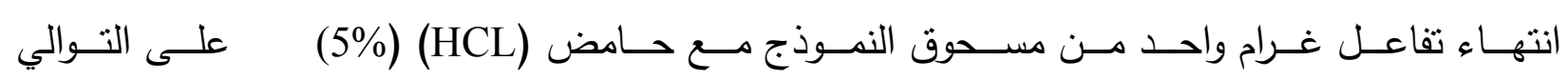

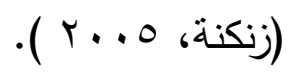

\section{الاراسة المعدنية لصخور تكوين البلاسبي:}

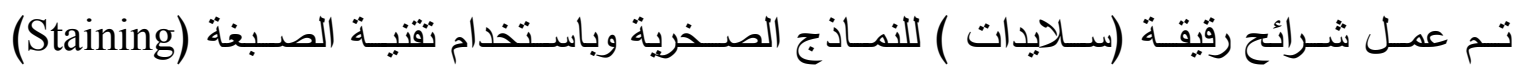
(Alizarin red S.) (Friedman ،1909)

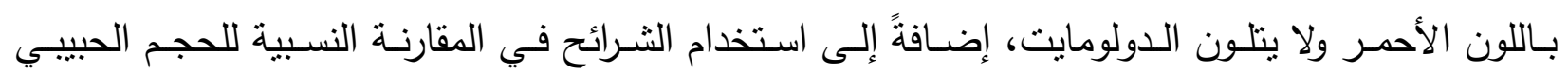

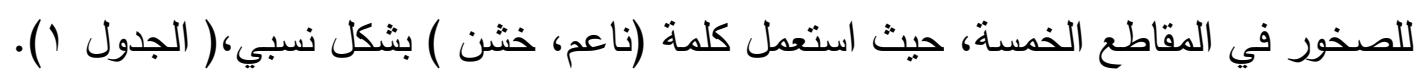

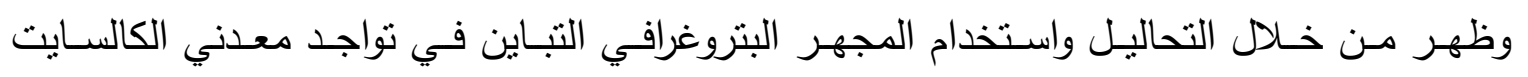
والدولومايت على طول الجناح الثمالي الثرقي للطية (الجدول ()). ويوضح الثكل (r) إن نسبة الكالسايت

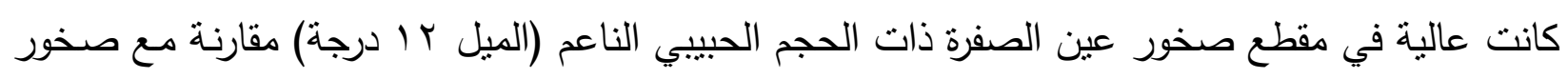

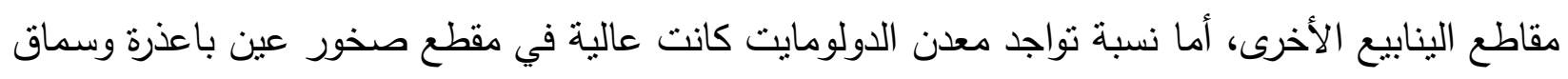

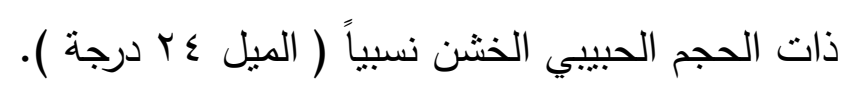

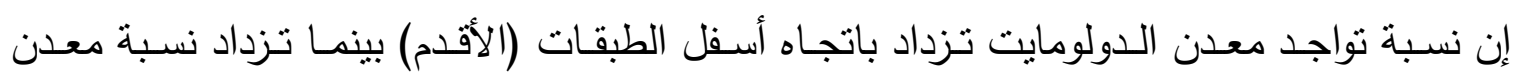

$$
\text { الكالسايت في الاتجاه الأعلى أب الأحدث ( الثكل ؟َ). }
$$




$$
\text { المجلة العراقية لعلوم الأرض- - المجلدی- العددץ- نتشرين الثاني ^... }
$$

إن الحجم الحبيبي الناعم وزيادة نسبة الكالسايت في مقطع صخور ينبوع عين الصفرة وقابلية الذوبان العالية للكالسـايت مقارنةً بالدولومايت في المحاليل المائية (ثابت ذوبان الكالسـايت = م عـــ، وثابت ذوبـان

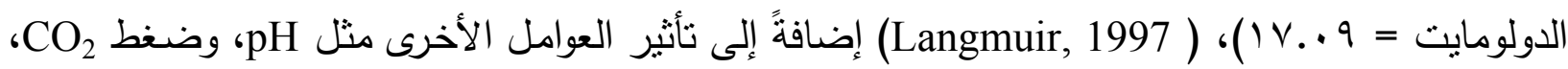
و الميل القليل وعليه فان جميع هذه العوامل أدت إلى زيادة ذوبان صخور تكوين البلاسبي لمقطع ينبوع عين الصفرة مقارنةً مع بقية المقاطع الصخرية للينابيع الأخرى.

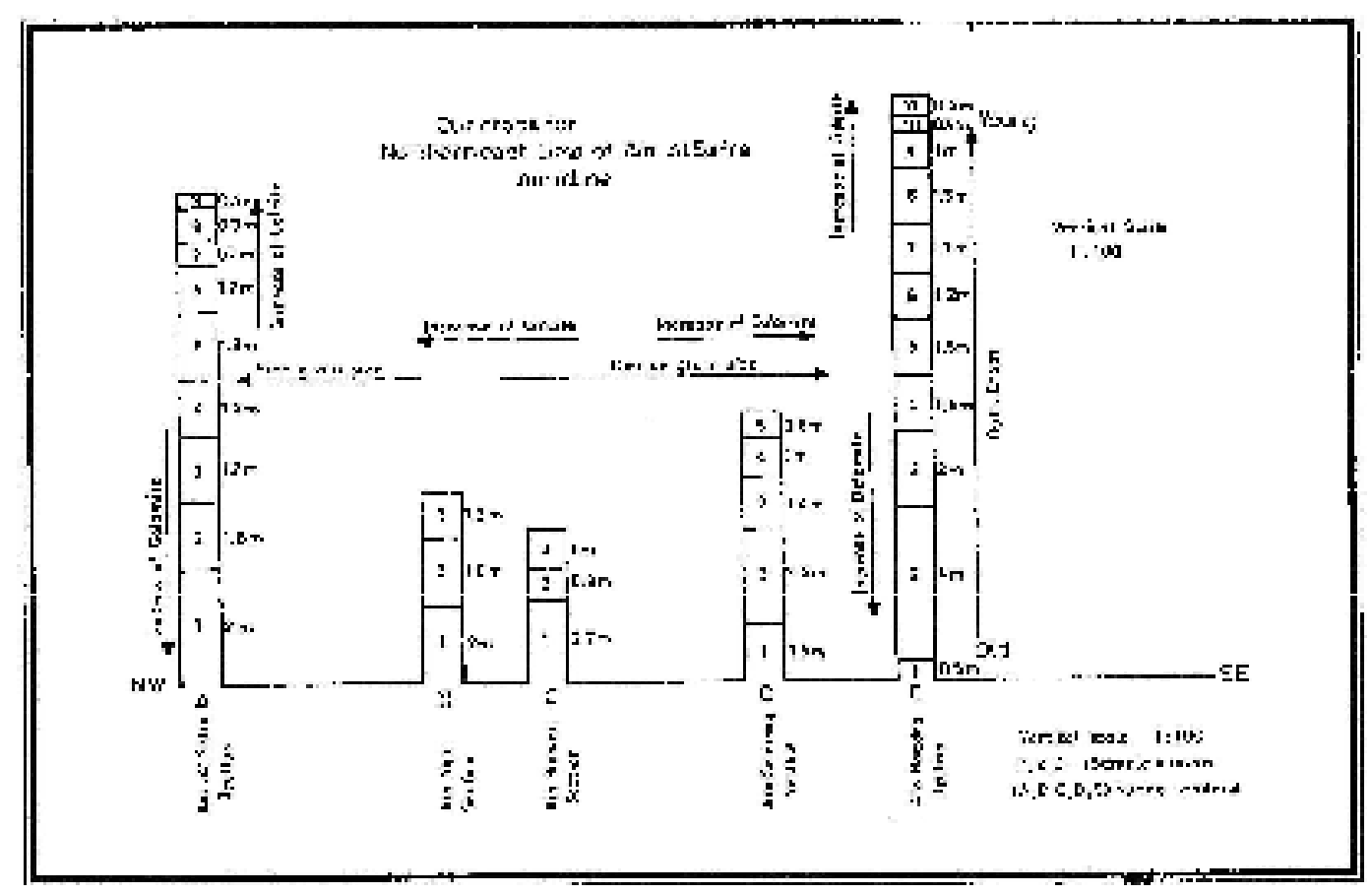

الثكل ب: توزيع العينـات الصخرية في مقاطع الدراسـة لتكوين البلاسبي لطية عين الصفرة المحدبـة، والحجم الحبيبي وتوزيع الكالسايت والدولومايت في الاتجاهين الأفقي و العمودي

الجدول ا: مقارنـة بـين معـدل النسـب المئويـة لمعـني الكالسـايت والـدولومايت ومعـدل النسـبة المئويـة لـ والحجم الحبيبي للنماذج الصخرية المأخوذة من مواقع الينابيع الخمسة في الدراسة الحالية

\begin{tabular}{|c|c|c|c|c|c|c|}
\hline $\begin{array}{c}\text { معدل } \\
\text { Dolomite } \\
\%\end{array}$ & $\begin{array}{c}\text { معدل } \\
\text { Calcite } \\
\%\end{array}$ & $\begin{array}{c}\text { معدل } \\
\mathrm{MgCO}_{3} \%\end{array}$ & $\begin{array}{c}\text { معدل } \mathrm{CaCO}_{3} \%\end{array}$ & الحبيبي & عداد & الموقع \\
\hline AT.r & 01.1 & r^.l & $T . . Y$ & 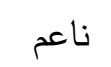 & 9 & ينبوع عين الصفرة \\
\hline Nr. & 09.1 & IV.V & $\Lambda \cdot . v$ & خشن & r & ينبوع عين أسقف \\
\hline rV.q & $07 . V$ & IV.z & N1. & خشن & r & ينبوع عين كروان \\
\hline $9 T . Y$ & $0 . \varepsilon$ & $\leq Y . T$ & $07 .$. & خشن خ & 0 & ينبوع عين سماق \\
\hline $9 . .9$ & $0 . \varepsilon$ & $\varepsilon 1 . \vee$ & $00 .$. & خشن خ & 11 & ينبوع عين باعذرة \\
\hline
\end{tabular}




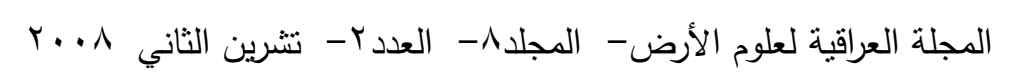

الاراسة الجيوكيميائية لصخور ومياه ينابيع الدراسة: من خلال ملاحظة تراكيز العنصرين الأثريين (Cu, Mn) للنماذج الصخرية لهقاطع الينابيع الخمسة

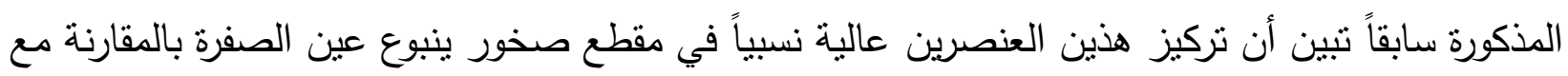

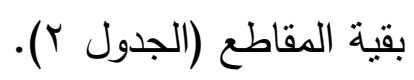
إن ذوبان أجزاء من صخور تكوين البلاسبي بفعل الدحاليل المائية التي تتحرك في الفواصل والثقوق

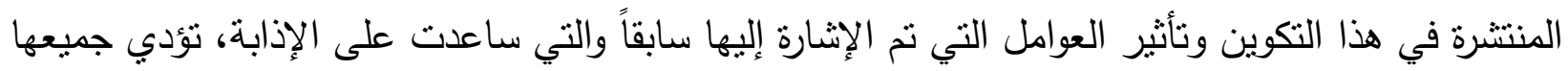

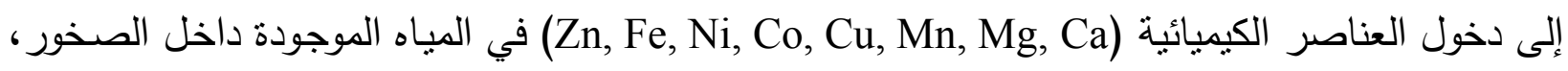
وتتحرك هذه المياه المحملة بالعناصر الكيميائية إلى حوض الينبوع، ونتاسب تراكيز هذه العناصر في مياه

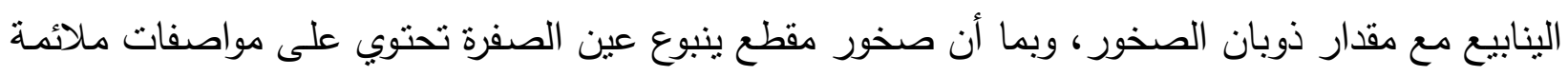

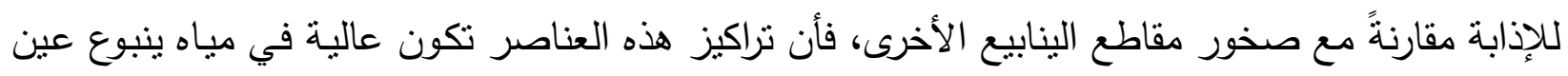

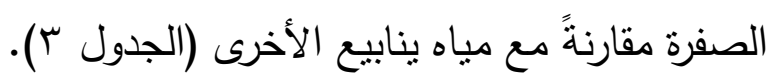

الجدول:r: معدل تراكيز العناصر الأثرية والاكاسيد الرئيسية في نماذج صخرية من المواقع الخمسة في جيل

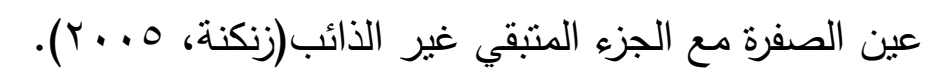

\begin{tabular}{|c|c|c|c|c|c|c|c|c|c|c|}
\hline $\begin{array}{l}\text { IR } \\
\text { \% }\end{array}$ & $\begin{array}{c}\mathrm{CO}_{2} \\
\%\end{array}$ & $\underset{\%}{\operatorname{MgO}}$ & $\underset{\%}{\mathrm{CaO}}$ & $\begin{array}{l}\text { Mn } \\
\text { ppm }\end{array}$ & $\begin{array}{c}\mathbf{C u} \\
\mathbf{p p m}\end{array}$ & $\begin{array}{c}\text { Co } \\
\text { ppm }\end{array}$ & $\begin{array}{c}\mathbf{N i} \\
\mathbf{p p m}\end{array}$ & $\begin{array}{c}\mathbf{F e} \\
\mathbf{p p m}\end{array}$ & $\begin{array}{c}\text { Zn } \\
\text { ppm }\end{array}$ & الموقع \\
\hline 4.37 & 42.7 & 18.2 & 33.8 & 48 & 6 & 21 & 20 & 597 & 15 & مقطع عين الصفرة \\
\hline 2.4 & 43.6 & 9.1 & $43 . .4$ & 33 & 4 & 18 & 48 & 598 & 17 & مقطع عين أسقف \\
\hline 2.1 & 43.6 & 7.6 & 45.6 & 30 & 2 & 14 & 39 & 455 & 19 & مقطع عين كروان \\
\hline 3.8 & 41.9 & 21.9 & 31.4 & 7 & 3 & 16 & 13 & 424 & 18 & مقطع عين سماق \\
\hline 5.7 & 42.5 & 20.1 & 30.9 & 12 & 3 & 10 & 11 & 378 & 11 & مقطع عين باعذرة \\
\hline
\end{tabular}

الجـدول بـ: معـدل تراكيـز العناصـر الأثريـة وعنصـري الكالسـيوم والمغنيسـيوم في ميـاه ينـابيع الدراســة

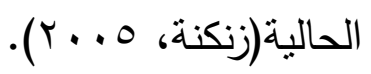

\begin{tabular}{|c|c|c|c|c|c|c|c|c|}
\hline $\begin{array}{c}\mathrm{Ca} \\
\mathrm{Mg} / \mathrm{L} \\
\end{array}$ & $\begin{array}{c}\mathrm{Mg} \\
\mathrm{Mg} / \mathrm{L} \\
\end{array}$ & $\begin{array}{c}\text { Mn } \\
\mathbf{M g} / \mathbf{L}\end{array}$ & $\begin{array}{c}\mathrm{Cu} \\
\mathrm{Mg} / \mathrm{L}\end{array}$ & $\begin{array}{c}\mathrm{Co} \\
\mathrm{Mg} / \mathrm{L} \\
\end{array}$ & $\begin{array}{c}\mathrm{Ni} \\
\mathrm{Mg} / \mathrm{L} \\
\end{array}$ & $\begin{array}{c}\mathrm{Fe} \\
\mathrm{Mg} / \mathrm{L}\end{array}$ & $\begin{array}{c}\mathrm{Zn} \\
\mathrm{Mg} / \mathrm{L} \\
\end{array}$ & الموقع \\
\hline 57.6 & 22.8 & 0.36 & 0.03 & 0.1 & 0.14 & 2.63 & 0.31 & مقطع عين الصفرة \\
\hline 55.2 & 10.0 & 0.06 & 0.004 & 0.001 & 0.05 & 0.12 & 0.041 & مقطع عين أسقف \\
\hline 49.6 & 15.5 & N.D & 0.001 & 0.001 & 0.05 & 0.06 & 0.026 & مقطع عين كروان \\
\hline 42.4 & 18.0 & N.D & 0.001 & 0.001 & 0.04 & 0.06 & 0.023 & مقطع عين سماق \\
\hline $38 . .4$ & 18.5 & N.D & 0.003 & 0.003 & 0.01 & 0.31 & 0.031 & مقطع عين باعذرة \\
\hline
\end{tabular}

N . D $=$ Not Detected 


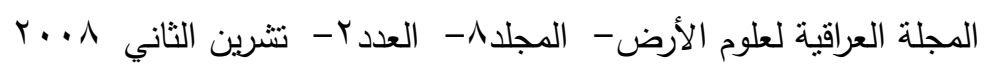

\section{الاستتتاجات}

1-يوجد تباين في النسب المئويـة للدولومايت والكالسـايت على طول الجناح الثمالي الثرقي لطية عين الصفرة في الاتجاهين الأفقي والعمودي.

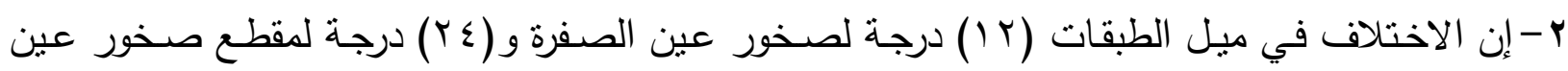

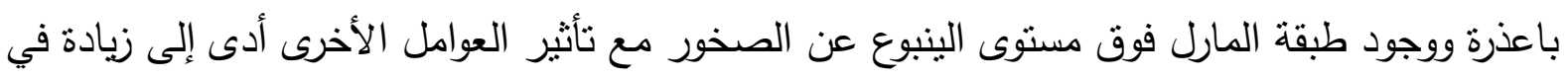

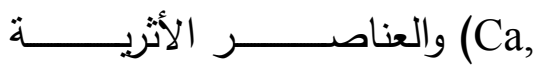
$\mathrm{Mg})$ لعز العناص تراكي (Mn, Cu, Co, Ni, Fe, Zn )

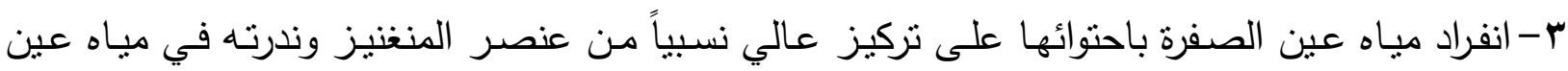
أسقف وعدم تواجد هذا العنصر في مياه الينابيع الأخرى.

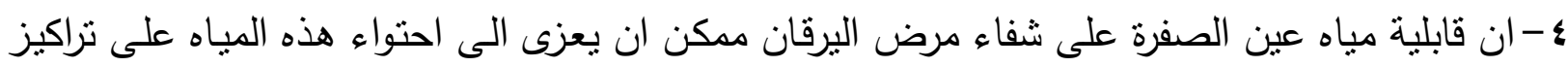

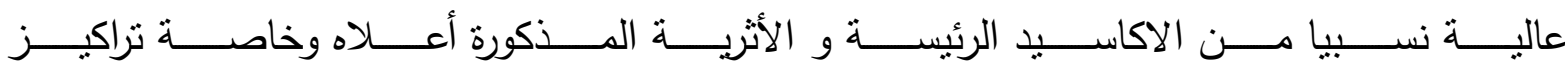
.(CaO, $\mathrm{MgO}, \mathrm{Mn})$

\section{التوصيات}

ا. الاهتمام بمياه ينبوع عين الصفرة ولذلك لأهميتها الكبيرة واحتوائها على عناصر كيميائية ضرورية من حيث معالجتها لمرضى اليرقان. r. إجراء دراسات واسعة للينابيع في المناطق الأخرى والاستفادة من الينابيع المعدنية لأغراض السياحة و الاستطباب.

\section{المصادر العربية}

الأمين، محمد حسين، ـ . . r. رحلة نيبور في العراق في القرن الثامن عشر، ترجمة عن الألمانية الدكتور

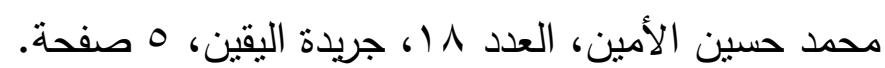

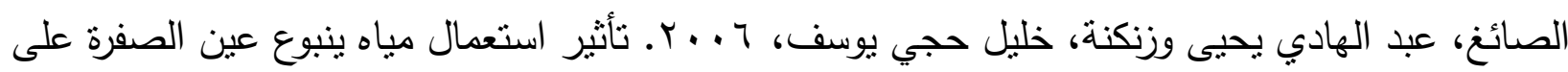
مرض اليرقان (أبو صفار) شمال العراق، المجلة العراقية لعلوم الأرض المجلد السادس العدد الثناني

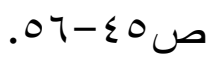

زنكنة، خليل حجي يوسف، ه . . r. دراسة جيوكيميائية لصخور مياه عيون جبل عين الصفرة. شمال العراق

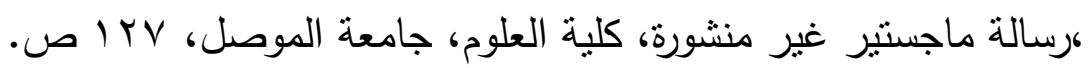




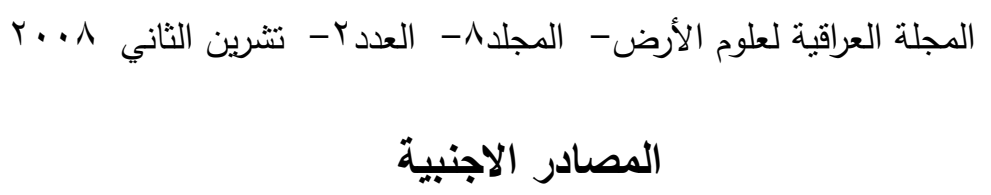

Al-Omari, F.S. and Sadek, A., 1973. Geological studies of Jebel Maqlub Area Northern Iraq, Geol. Soc. Iraq, Vol. 71, pp. 66-82.

Barwary, A.M., 1983. Report on Geological Mapping Survey of Khasir- Comel Area, Unpublished, SOM, report, No.1137, Part1, SOM, library, pp.6-23.

Blaurock-Busch, E., 1997. The Clinical Effects of Manganese (Mn). Mineral and Ttrace Element Analysis, Laboratory and Clinical.

Buday, T. and Jassim, S.Z., 1987. Final Report on Regional Geological Survey of Iraq. Unpubllished Rep., SOM Library, Baghdad, Iraq.

Friedman, G.N., 1959. Identification of Carbonate Minerals as Staining Methods, Jour. Sedim. Petrology. Vol. 29, pp. 87-97.

Ibrahim, I.S. and Omer, A.A., 1994. A Proposed Mechanism of Folding for Ainsafra Anticline, N. Iraq, Iraqi Geological Jornal , 27(3), pp.76-89.

Kaplan, L.A., Pesce, Aj., 1989. Clinical Chemistry Theory Analysis and Correlation $2^{\text {nd }}$ ed. Mos by Co.

Langmuir, D., 1997. Aqueous Environmental Geochemistry, Prentice Hall, New York, $480 \mathrm{p}$.

Maureen, K.S., 2001. Liver Problems. www. Bay to bay. com.

Muller, G., 1956 Sedimentary Petrology Part1, Methods of Sedimentary Petrology: Translated by Hansulrich. Schmincke, Hafner, 283p.

Todd, D. k ., 1980. Ground Water Hydrology, ( $2^{\text {nd }}$, Ed.), 338 P. John Willey. 